\title{
Osteophilic properties of bone implant surface modifications in a cassette model on a decorticated goat spinal transverse process
}

Citation for published version (APA):

van Oirschot, B. A. J. A., Eman, R. M., Habibovic, P., Leeuwenburgh, S. C. G., Tahmasebi, Z., Weinans, H., Alblas, J., Meijer, G. J., Jansen, J. A., \& van den Beucken, J. J. J. P. (2016). Osteophilic properties of bone implant surface modifications in a cassette model on a decorticated goat spinal transverse process. Acta Biomaterialia, 37, 195-205. https://doi.org/10.1016/j.actbio.2016.03.037

Document status and date:

Published: 01/06/2016

DOI:

10.1016/j.actbio.2016.03.037

Document Version:

Publisher's PDF, also known as Version of record

Document license:

Taverne

Please check the document version of this publication:

- A submitted manuscript is the version of the article upon submission and before peer-review. There can be important differences between the submitted version and the official published version of record.

People interested in the research are advised to contact the author for the final version of the publication, or visit the DOI to the publisher's website.

- The final author version and the galley proof are versions of the publication after peer review.

- The final published version features the final layout of the paper including the volume, issue and page numbers.

Link to publication

\footnotetext{
General rights rights.

- You may freely distribute the URL identifying the publication in the public portal. please follow below link for the End User Agreement:

www.umlib.nl/taverne-license

Take down policy

If you believe that this document breaches copyright please contact us at:

repository@maastrichtuniversity.nl

providing details and we will investigate your claim.
}

Copyright and moral rights for the publications made accessible in the public portal are retained by the authors and/or other copyright owners and it is a condition of accessing publications that users recognise and abide by the legal requirements associated with these

- Users may download and print one copy of any publication from the public portal for the purpose of private study or research.

- You may not further distribute the material or use it for any profit-making activity or commercial gain

If the publication is distributed under the terms of Article $25 \mathrm{fa}$ of the Dutch Copyright Act, indicated by the "Taverne" license above, 
Full length article

\title{
Osteophilic properties of bone implant surface modifications in a cassette model on a decorticated goat spinal transverse process
}

\author{
Bart A.J.A. van Oirschot ${ }^{\mathrm{a}, \mathrm{d}}$, Rhandy M. Eman ${ }^{\mathrm{b}}$, Pamela Habibovic ${ }^{\mathrm{c}}$, Sander C.G. Leeuwenburgh ${ }^{\mathrm{a}}$, \\ Zeinab Tahmasebi ${ }^{\mathrm{c}}$, Harrie Weinans ${ }^{\mathrm{b}}$, Jacqueline Alblas ${ }^{\mathrm{b}}$, Gert J. Meijer ${ }^{\mathrm{d}}$, John A. Jansen ${ }^{\mathrm{a}, \mathrm{d}}$, \\ Jeroen J.J.P. van den Beucken ${ }^{\mathrm{a}, *}$ \\ a Department of Biomaterials, Radboudumc, Nijmegen, The Netherlands \\ ${ }^{\mathrm{b}}$ Department of Orthopedics, University Medical Center Utrecht, The Netherlands \\ ${ }^{\mathrm{c}}$ Department of Tissue Regeneration, MIRA Institute for Biomedical Technology and Technical Medicine, University of Twente, The Netherlands \\ ${ }^{\mathrm{d}}$ Department for Implantology and Periodontology, Radboudumc, Nijmegen, The Netherlands
}

\section{A R T I C L E I N F O}

\section{Article history:}

Received 12 November 2015

Received in revised form 21 March 2016

Accepted 24 March 2016

Available online 24 March 2016

\section{Keywords:}

Biomaterials

Titanium implant

Surface modifications

Calcium phosphate

Goat model

\begin{abstract}
A B S T R A C T
This study comparatively evaluated the osteophilic capacity of 17 different surface modifications (i.e. fourteen different chemical modifications via ceramic coatings and three different physical modifications via surface roughness) for titanium (Ti) surfaces. All surface modifications were subjected to physicochemical analyses and immersion in simulated body fluid (SBF) for coating stability assessment. Subsequently, a bone conduction chamber cassette model on the goat transverse process was used for comparative in vivo analysis based on bone responses to these different surface modifications after twelve weeks. Histological and histomorphometrical analyses in terms of longitudinal bone-to-implant contact percentage (BIC\%), relative bone area (BA\%) were investigated within each individual channel and maximum bone height $(\mathrm{BH})$. Characterization of the surface modifications showed significant differences in surface chemistry and surface roughness among the surface modifications. Generally, immersion of the coatings in SBF showed net uptake of calcium by thick coatings ( $>50 \mu \mathrm{m}$; plasma-sprayed and biomimetic coatings) and no fluctuations in the SBF for thin coatings $(<50 \mu \mathrm{m})$. The histomorphometrical data set demonstrated that only plasma-sprayed CaP coatings performed superiorly regarding BIC\%, BA $\%$ and $\mathrm{BH}$ compared to un-coated surfaces, irrespective of surface roughness of the latter. In conclusion, this study demonstrated that the deposition of plasma-sprayed CaP coating with high roughness significantly improves the osteophilic capacity of titanium surfaces in a chamber cassette model.
\end{abstract}

\section{Statement of Significance}

For the bone implant market, a large number of surface modifications are available on different types of (dental and orthopedic) bone implants. As the implant surface provides the interface at which the biomaterial interacts with the surrounding (bone) tissue, it is of utmost importance to know what surface modification has optimal osteophilic properties. In contrast to numerous earlier studies on bone implant surface modifications with limited number of comparison surfaces, the manuscript by van Oirschot et al. describes the data of in vivo experiments using a large animal model that allows for direct and simultaneous comparison of a large variety of surface modifications, which included both commercially available and experimental surface modifications for bone implants. These data clearly show the superiority of plasma-sprayed hydroxyapatite coatings regarding bone-to-implant contact, bone amount, and bone height.

๔ 2016 Acta Materialia Inc. Published by Elsevier Ltd. All rights reserved.
* Corresponding author at: Radboudumc, Biomaterials (309), Philips van Leijdenln 25, 6525 EX Nijmegen, The Netherlands.

E-mail address: jeroen.vandenbeucken@radboudumc.nl (J.J.J.P. van den Beucken).

\section{Introduction}

An expanding and aging world population has increased the demand for implantable devices and scaffolds to replace damaged tissues and restore tissue function [1,2]. These implants must be 
designed so they are easy to implant with minimal post-operative complications. Further, these implants must be safe, reliable, and long lasting in patients with varied health status [3,4]. In the field of oral implantology, increasing numbers of dental implants are placed globally to support (complete or partial) prosthetic devices [5]. Long-term implant survival and success rates (up to $90 \%$ after 10 -years follow-up) have been reported for implants under favorable clinical conditions [6]. Implant failure, however remains significant in patients with chronic medical conditions, impaired bone healing (i.e. osteoporosis), or in anatomical sites with insufficient bone quantity and quality $[7,8]$.

The challenge then is to achieve long term implant success in medically compromised patients. In order to achieve this goal, osteophilic implants i.e. implants that favor bone apposition, are required [9]. Since the implant surface directly interacts with bone tissue, research has focused on modifying the implant surface to improve its osteophilic characteristics with the goal of inducing early peri-implant bone formation [10-12]. These osteophilic implant surface modifications focus on manipulation of physical (roughness) and/or chemical properties of the metallic implant surface (i.e. titanium or titanium-alloy). These modification methods are based on either subtractive (i.e. grit blasting, acid etching) [13] or additive (i.e. coating deposition) procedures [14].

Surface roughening is a popular subtractive modification method because rough surfaces have a larger contact area for interaction with bone tissue in comparison to smooth surfaces [15]. Further, surface roughening creates micro-porosities and small etching grooves that have been hypothesized to enhance protein adhesion and stimulate cell migration on the implant surface facilitating early bone formation [16,17].

Additive techniques utilizing bioactive ceramics (e.g. calcium phosphate, $\mathrm{CaP}$ ) on implant surfaces have shown superior osteophilicity compared to non coated surfaces [18-21]. It has been hypothesized that this enhanced osteophilicity is related to the (superficial) dissolution of the CaP coating that results in calcium $\left(\mathrm{Ca}^{2+}\right)$ and phosphate $\left(\mathrm{PO}_{4}^{3-}\right)$ ion release in the peri-implant region [22]. Mechanistic studies have shown that $\mathrm{Ca}^{2+}$ ions have a positive effect on the differentiation of osteoprogenitor cells [23-25]. Further, both ions enhance the precipitation of a carbonated calcium phosphate layer that has high crystallographic resemblance to natural bone mineral [26,27]. Several studies have shown that the osteophilic properties of the ceramic coating are influenced by the crystal phase, chemical composition and crystallinity of the applied CaP ceramic [28,29]. Hydroxyapatite (HA) [30], tricalcium phosphate (TCP) [31], and octacalcium phosphate (OCP) [32], have been successfully used for the deposition of ceramicbased coatings. In addition to CaP coatings, bioactive silicatebased glass (BG) coatings are thought to demonstrate osteophilic characteristics $[33,34]$. It has been demonstrated that the formation of a hydrated silica layer and hydroxyl carbonate apatite on the glass surface have an osteopromotive effect on osteoblast proliferation and differentiation [35].

Ceramic-based coatings can be deposited through a variety of techniques, including plasma-spraying, magnetron sputtering, or pulsed laser deposition (PLD) [15,36]. Plasma-spraying is a popular procedure in the field of dentistry and orthopedics for the deposition of CaP-based coatings on metallic bone implants. Numerous in vivo studies have been published on the beneficial biological performance of plasma-sprayed CaP surfaces [37-39]. However, clinical use of these coatings is hampered by concerns regarding coating delamination and fragmentation at the implant/coating interface. This delamination and fragmentation jeopardizes the long-term performance of these implants [40]. Magnetron sputtering and pulsed laser deposition can overcome these problems by generating thin, adherent coatings while preserving the osteophilic properties of the CaP ceramic $[41,42]$.
Additionally, wet-chemical coating techniques, such as electrospray deposition (ESD) or coating deposition via biomimetic precipitation, have been used for coating deposition of CaP ceramics under physiological conditions (i.e. low temperature and pressure). Not only do these techniques allow for simultaneous incorporation of organic components and therapeutic agents into CaP ceramic coating [43], but these techniques also make it possible to deposit coatings on scaffolds of complex 3D architectures that are frequently used for regeneration of craniofacial skeletal defects [43]. As these techniques allow for deposition of less stable CaP phases, partial coating dissolution and release of incorporated compound can induce a local anabolic effect, which stimulates the bone remodeling process at the peri-implant interface [44].

All aforementioned surface modifications and coating procedures have shown benefit during the early process of periimplant bone formation. Straightforward comparison of different in vitro and in vivo results for each individual study, however, has proven difficult for several reasons. First, there is a lack of suitable models that allow simultaneous evaluation of multiple surface modifications. Second, experiment specific parameters and differences in bone healing in each experimental setup can influence the performance of a coating or surface modification. Third, most of the experimental animal models only allow inclusion of a limited number of experimental groups. In response to these challenges, this study was designed to evaluate the osteophilic capacity of a broad range of seventeen different surface modifications within one in vivo experimental setup. For this purpose, a bone conduction chamber cassette model was used on the transverse process of a goat, a common model used for pre-clinical evaluation of bone implant surface modifications. This model allows for simultaneous comparison of different surface modifications, and the effects on bone ingrowth and bone metabolism under unloaded conditions $[45,46]$. In this study, we compared the osteophilic capacity of different ceramic-based coatings in comparison to different titanium surfaces obtained via subtractive procedures (machined (Ti), grit blasted (GB), grit blasted acid etched (GAE)). Bone response to the different implants was evaluated using histological and histomorphometrical analyses in terms of longitudinal bone-to-implant contact percentage (BIC\%), relative bone area (BA $\%$ ) within each individual channel and maximum bone height $(\mathrm{BH})$.

\section{Materials and methods}

\subsection{Research objectives and experimental study design}

This study evaluated the osteophilic capacity of different ceramic-based coatings compared to titanium surfaces obtained through different subtractive procedures within one in vivo experimental setup. For this purpose, a previously designed bone conduction chamber model on the goat transverse processes was used [45]. The sample size needed for the study was calculated using online software [61]. An effect size (f) of 0.2, an error probability $\alpha=0.05$, standard deviation (SD) of 0.1 , and a power (P) of 0.85 were assumed. This gave a minimal required sample size per coating type $(n)$ of 10 .

\subsection{Sample preparation and characterization}

Polyacetal chamber cassettes designed for bone conduction evaluation were used [46]. Each cassette contained ten titanium plates that formed five osteoconductive channels that each had a diameter of $0.5 \mathrm{~mm}$ in width. After cassette fixation on the transverse processes, the bottom component of the channels was exposed to the underlying bone while the top component was covered by overlying soft tissue. 
(a)
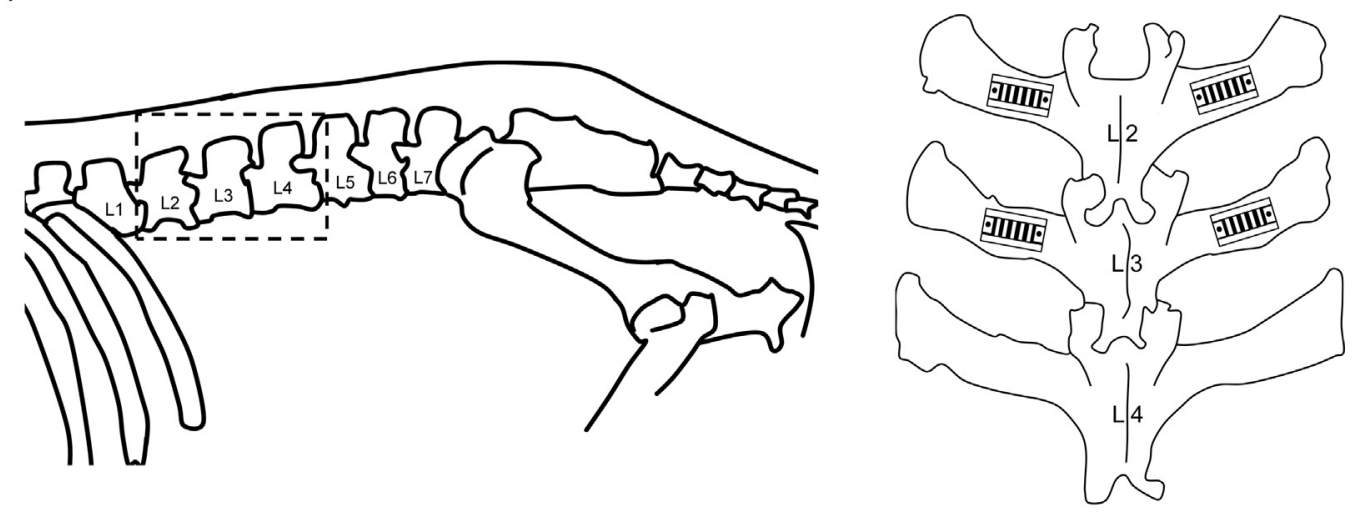

(b)
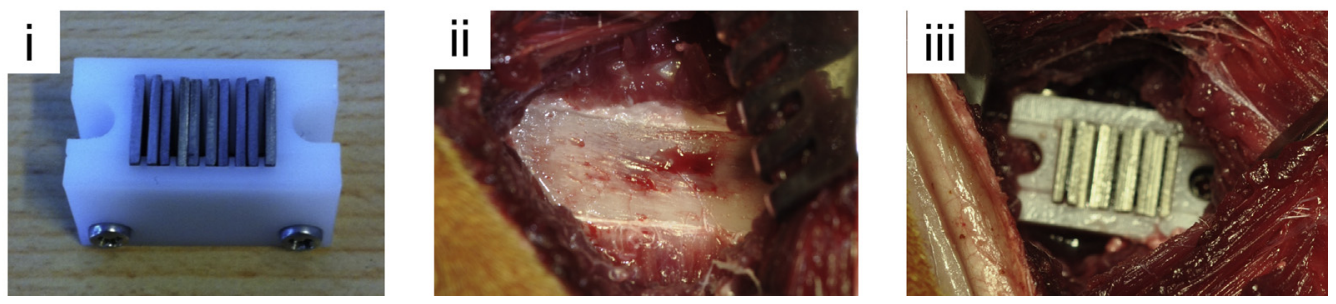

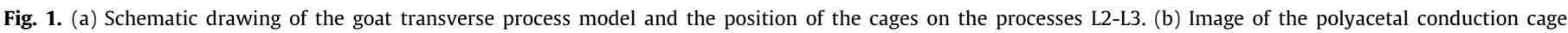
containing the titanium plates, the exposed trabecular bone and the fixation of the cage on the transverse process.

Table 1

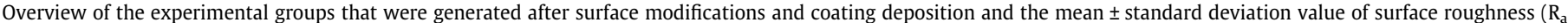
$\mu \mathrm{m})$ measurements. Ten samples were used in each experimental group.

\begin{tabular}{|c|c|c|c|c|}
\hline Substrate & Surface & Coating technology & Group & $\mathrm{Ra}(\mu \mathrm{m}) \pm \mathrm{SD}$ \\
\hline Titanium & $\begin{array}{l}\text { Machined } \\
\text { Grit Blasted (GB) } \\
\text { Grit Blasted/Acid Etched (GAE) }\end{array}$ & None used & $\begin{array}{l}\mathrm{Ti} \\
\mathrm{GB} \\
\text { GAE }\end{array}$ & $\begin{array}{l}0.77 \pm 0.08 \\
1.22 \pm 0.03 \\
1.04 \pm 0.13\end{array}$ \\
\hline Titanium & Grit Blasted & Pulsed Laser Deposition (PLD) & $\begin{array}{l}\text { PLD HA-L } \\
\text { PLD HA-H }\end{array}$ & $\begin{array}{l}1.06 \pm 0.08 \\
1.28 \pm 0.01\end{array}$ \\
\hline Titanium & Grit Blasted & Electrospray Deposition (ESD) & ESD HA & $1.30 \pm 0.07$ \\
\hline Titanium & Grit Blasted & Plasma-Spraying & $\begin{array}{l}\text { Plasma HA-L } \\
\text { Plasma HA-M } \\
\text { Plasma HA-H }\end{array}$ & $\begin{array}{l}6.95 \pm 0.72^{*} \\
6.48 \pm 1.12^{*} \\
7.13 \pm 0.56^{*}\end{array}$ \\
\hline Titanium & Grit Blasted & Biomimetic (BIO) & $\begin{array}{l}\text { BIO-HA } \\
\text { BIO-OCP } \\
\text { BIO OCP-Sr-1 } \\
\text { BIO OCP-Sr-h }\end{array}$ & $\begin{array}{l}1.20 \pm 0.06 \\
1.24 \pm 0.08 \\
1.17 \pm 0.12 \\
1.64 \pm 0.19\end{array}$ \\
\hline Titanium & Grit Blasted & Magnetron Sputtering & $\begin{array}{l}\text { Sputter HA } \\
\text { Sputter TCP } \\
\text { Sputter HABG l } \\
\text { Sputter HABG h }\end{array}$ & $\begin{array}{l}1.23 \pm 0.03 \\
1.13 \pm 0.01 \\
1.03 \pm 0.04 \\
1.27 \pm 0.06\end{array}$ \\
\hline
\end{tabular}

Statistical significance found $(\mathrm{p}<0.05)$.

Commercially available machined titanium plates (Ti-6Al-4V; G. Jansen BV, Valkenswaard, The Netherlands) were cut into rectangular shaped samples $(12 \times 9 \times 1 \mathrm{~mm})$ to fit tightly into the chamber cassettes (Fig. 1b). The samples were either left untreated or $\mathrm{Al}_{2} \mathrm{O}_{3}$ grit blasted $(25-75 \mu \mathrm{m}$; Poli Korund, Memodent, Enschede, The Netherlands) on one side to create microroughened surfaces. The titanium plates were cleaned ultrasonically in acetone (15 $\mathrm{min})$ and isopropanol (15 min), and then air-dried. Finally, coating procedures were applied according to Table 1.

In the present study, ceramic coatings were generated based on different phases of CaP ceramics (i.e. HA, OCP and TCP), as a composite coating incorporating bioactive glass or by the addition of therapeutic agents (i.e. strontium). The physicochemical and morphological composition of the different coatings are described in detail in Table 2. Pulsed laser deposited (PLD) sol-gel Hydroxyapatite (HA) coatings, were provided by Solmates, Enschede, The Netherlands. PLD HA coatings of low (L) and high (H) crystallinity were obtained by adjusting deposition parameters [62]. Electrostatic Spray deposited (ESD) HA coatings were generated using a commercially available ESD device (ES-2000S, Fuence Co., Ltd., Japan) at the department of Biomaterials, Radboudumc, Nijmegen, The Netherlands. For coating deposition, carbonate apatite nanoparticles (20 nm) were obtained from Berkeley Advanced Biomaterials Inc. (San Leandro, CA, USA). Coatings were produced as previously described by De Jonge et al. [63] Temperature was set 
Table 2

Net calcium $\left(\mathrm{Ca}^{2+}\right)$ fluctuations in SBF during a 14 day incubation period in SBF $(n=3)$.

\begin{tabular}{lccrr}
\hline \multicolumn{5}{c}{ Net $\mathrm{Ca}^{2+}$ in SBF solution (ug) } \\
\cline { 2 - 5 } & Day 7 (mean \pm SD) & \multicolumn{2}{l}{ Day 14 (mean \pm SD) } \\
\hline PLD HA-L & -167.1 & 4.8 & -150.7 & 1.7 \\
PLD HA-H & -4.6 & 0.7 & 5.8 & 3.3 \\
ESD HA & -9.7 & 0.0 & 9.3 & 1.4 \\
Plasma HA-L & -78.8 & 0.6 & -67.6 & 0.3 \\
Plasma HA-M & -147.9 & 0.7 & -151.1 & 0.9 \\
Plasma HA-H & -150.9 & 0.8 & -163.1 & 1.1 \\
BIO-HA & -198.6 & 0.3 & -193.4 & 0.7 \\
BIO-OCP & -173.5 & 0.1 & -170.1 & 0.1 \\
BIO OCP-Sr-l & -175.5 & 0.8 & -173.6 & 0.4 \\
BIO OCP-Sr-h & -174.4 & 0.2 & -175.4 & 1.0 \\
Sputter HA & 12.2 & 2.3 & 18.1 & 1.1 \\
Sputter TCP & 1.4 & 2.8 & 10.1 & 4.3 \\
Sputter HABG l & -100.3 & 0.8 & -100.8 & 2.0 \\
Sputter HABG h & -0.4 & 0.6 & 1.4 & 0.7 \\
\hline
\end{tabular}

at $25^{\circ} \mathrm{C}$, the nozzle-to-substrate distance was fixed at $40 \mathrm{~mm}$ and spraying time was $30 \mathrm{~min}$. After deposition, samples were airdried. Plasma-sprayed CaP ceramic coatings of low (L), medium (M) and high $(\mathrm{H})$ crystallinity were provided by CAM Bioceramics, Leiden, The Netherlands [64]. Biomimetic coatings were generated at MIRA-Institute for Biomedical Technology and Technical Medicine, University of Twente, Enschede, The Netherlands. Biomimetic apatite coatings were deposited in a two-stage procedure by heterogeneous nucleation of a thin and amorphous calcium phosphate layer in supersaturated Simulated Body Fluid (SBF) [65]. Octacalcium phosphate-strontium coatings with a low (l) or high (h) concentration of strontium (OCP-Sr-l, OCP-Sr-h) were generated by immersing samples in SBF solution followed by a simulated calcifying solution, as described previously [66-68]. After coating deposition, all samples were cleaned with deionized water and air dried overnight. For radiofrequent magnetron sputtercoatings, a commercially available sputter unit was used (Edwards High Vacuum ESM100 system, Sussex, UK) at the department of Biomaterials (Radboudumc, Nijmegen, The Netherlands). The target materials for coating deposition were HA granulated powder (Cam Bioceramics BV, Leiden, The Netherlands) or bioactive glass (BG) S53P4 granulates (Vivoxid Ltd. Turku, Finland). For the Tricalcium phosphate (TCP) coatings, cupper discs with a plasmasprayed $\beta$-TCP coating were used as a target material. Two composite HABG were generated containing a low (l) or high (h) concentration of bioactive glass (HABG l, HABG $h$ ). In order to obtain coatings with a comparable thickness, coating deposition procedures varied in time (HA: $4 \mathrm{~h}$, TCP: $2 \mathrm{~h}$, HABG l: $6 \mathrm{~h}$, HABG h: $6 \mathrm{~h}$ ) as described by Wolke et al. (1994) [69]. After processing, all TCP, HABG sputtered coatings received an additional heattreatment for $2 \mathrm{~h}$ at $650^{\circ} \mathrm{C}$. HA coatings were heat treated for $2 \mathrm{~h}$ at $550{ }^{\circ} \mathrm{C}$. Subsequently, all sputter coatings were autoclaved.

Average surface roughness value (Ra) and coating thickness were determined for each experimental group using a Universal Surface Tester (UST; Innowep, Würzburg, Germany). Fouriertransform infrared spectroscopy (FTIR, Perkin-Elmer, Massachusetts, USA) and X-ray diffraction (XRD, Philips $\theta-20$ diffractometer) were used to monitor crystal phase crystallinity and the molecular structure of the deposited coatings. Micro-porosity and qualitative surface characterization were carried out by using a backscattered electron microscopy (BSEM, XL30, ESEM-FEG, Philips, Eindhoven, The Netherlands).

Subsequently, the cassettes were aseptically assembled (Fig. 1b). The position of the surface modifications was randomly distributed on each cassette to prevent potential scaffold position confounding on the transverse process. Finally, the assembled cassettes containing all surface modified titanium plates were sterilized using low temperature ethylene oxide (EO) gaseous sterilization (Synergy Health plc, Venlo, The Netherlands).

\subsection{In vitro incubation in simulated body fluid (SBF)}

The in vitro dissolution of the coatings was evaluated in conventional SBF with an ionic composition almost equal to human plasma [79]. Ionic concentrations of the SBF were $142.0 \mathrm{mM} \mathrm{Na}^{+}$, $5.0 \mathrm{mM} \mathrm{K}$, $1.5 \mathrm{mM} \mathrm{Mg}{ }^{2+}, 2.5 \mathrm{mM} \mathrm{Ca}^{2+}, 147.8 \mathrm{mM} \mathrm{Cl}^{-}, 4.2 \mathrm{mM}$ $\mathrm{HCO}_{3}^{2-}, 1.0 \mathrm{mM} \mathrm{HPO}_{4}^{2-}$, and $0.5 \mathrm{mM} \mathrm{SO}{ }_{4}^{2-}$. Tris- $\mathrm{HCl}$ served as a buffer to maintain a constant $\mathrm{pH}$ value of 7.4. The coated Ti samples $(\mathrm{n}=3)$ were immersed in $5 \mathrm{~mL}$ of SBF in $10 \mathrm{ml}$ tubes for up to 14 days. SBF temperature was maintained at $37^{\circ} \mathrm{C}$ and incubation was performed on a shaking table. At 7 and 14 days, $0.5 \mathrm{ml}$ of SBF was sampled for analysis of calcium concentration using a biochemical calcium assay (orthocresolphtalein complexone; Sigma). For the biochemical assay, $10 \mu \mathrm{L}$ of sample or standard was pipetted in a 96 -well plate, followed by the addition of $300 \mu \mathrm{L}$ working solution. Working solution consisted of $5 \mathrm{~mL}$ of orthocresolphtalein complexone solution, $5 \mathrm{~mL}$ of $14.8 \mathrm{M}$ ethanolamine/boric acid buffer (pH.11), $2 \mathrm{~mL}$ of 8-hydroxyquinoline $(1 \mathrm{~g}$ in $20 \mathrm{~mL}$ $95 \%$ ethanol), and $88 \mathrm{~mL}$ of MilliQ. For the standard curve, serial dilutions of calcium stock $\left(\mathrm{CaCl}_{2}\right)$ were prepared to final concentrations of $0-100 \mu \mathrm{g} / \mathrm{mL}$. The plates were incubated at room temperature for $10 \mathrm{~min}$ and the absorbance was afterwards read using an ELISA microplate reader at $570 \mathrm{~nm}$. The obtained concentrations were converted to net calcium fluctuations in the SBF liquid via the total SBF volume and corrected for calcium amount in pristine SBF. In this way, positive values indicate net release of calcium from the coating into the SBF and negative values indicate net uptake of calcium from the SBF onto the coating.

\subsection{Animals and surgical procedure}

After the approval of the ethics committee of the Radboudumc (Nijmegen, The Netherlands; DECABC 2011.III.006), ten adult Dutch Saane milk goats (weight $\sim 60 \mathrm{~kg}$, age $\sim 24$ months) were purchased. National guidelines for care and use of laboratory animals were observed. The animals were allowed to acclimatize for four weeks, after which surgical procedures were performed under general anesthesia. After intubation, the animals received a preoperative subcutaneous injection of prophylactic antibiotic Albipen ${ }^{\circledR}(15 \%, 3 \mathrm{ml} / 50 \mathrm{~kg}$, Intervet BV, Boxmeer, The Netherlands) to reduce the risk of peri-operative infections. General anesthesia was achieved and maintained by Isoflurane ${ }^{\circledR}$ (Rhodia Organique Fine Limited, Avonmouth, Bristol, England). Prior to surgery and general anesthesia, the skin was shaved and cleaned with a $10 \%$ povidone-iodine solution. The experimental setup and surgical approach have been described in detail by Wilson et al. [45]. In brief, a midline skin incision was made from T1 to T5 to expose the fascia. Then, the attached muscles were bilaterally retracted to expose the underlying transverse processes L2 and L3 (Fig. 1a). After decortication of the processes using a bone rasp, the trabecular bone was flattened to create an even surface for placement of the cassettes. One cassette was mounted on each transverse process. Two pilot holes were drilled under saline irrigation, and two self-tapping screws were used for cage attachment (Fig. 1b). After the cages were mounted, light finger pressure was applied to the titanium plates to ensure direct contact with the underlying trabecular bone. Subsequently, the muscles, fascia and skin were closed in layers using resorbable sutures (Vicryl 4.0, Ethicon Products, Amersfoort, The Netherlands). Immediately and for three consecutive days after surgery, all goats received a subcutaneous injection of Albipen $^{\circledR}(7.5 \mathrm{ml} / 50 \mathrm{~kg}$, Intervet BV, Boxmeer, The Netherlands) to reduce post-operative infections and Temgesic ${ }^{\circledR}$ 
(0.015 mg/kg; Reckitt Benckiser Healthcare, Hull, England) to reduce post-operative pain.

\subsection{Implant retrieval and analysis}

After healing for 12 weeks, the animals were euthanized by an overdose of Nembutal ${ }^{\circledR}$ (Apharmo, Arnhem, The Netherlands), and the transverse processes containing the cassettes were retrieved. The cassettes were first stored in $4 \%$ formaldehyde for one week, then cassettes were dehydrated stepwise starting at $70 \%$ up to $100 \%$ ethanol solution. Cassettes were then embedded in methyl methacrylate (MMA, Technovit ${ }^{\circledR}$, H9100, Heraeus Kulzer, Haarlem, The Netherlands). Subsequently, three centrally located, non decalcified, thin longitudinal sections $(10-15 \mu \mathrm{m})$ were made along the axis of the transverse process using a modified sawing microtome technique [70]. Sections were then etched by EtOH/ $\mathrm{HCl}$ and stained with methylene blue/basic fuchsin. Sections were then evaluated histologically (25x magnification) for total tissue response and bone formation in the channels using a light microscope (Axio Imager Microscope Z1, Carl Zeiss Micro imaging GmbH, Göttingen, Germany). For histomorphometrical analysis, digital image analysis software (Leica Qwin Pro-image analysis software, Leica Imaging Systems, Cambridge, UK) was used. The osteophilic capacity of each surface condition was determined by setting an individual region of interest for each channel.

A custom macro was used to determine maximum bone height (bone peak), bone-to-implant contact (BIC\%) along the total length of the channel and the relative bone area (BA\%) in each channel (Fig. 2a-c). The average measurement based on three histological sections from each sample was used for statistical analysis.

\subsection{Statistical analysis}

The histomorphometrical parameters (BIC\%, BA\% and $\mathrm{BH}$ ) are displayed in box plots and statistically analyzed using Prism 5 (GraphPad Software Inc. San Diego, CA, USA). Mean values and standard deviations (SD) were calculated. The method of Kolmogorov and Smirnov was used to confirm that the data were sampled from populations that follow Gaussion distributions. For comparison of surface conditions on histomorphometric parameters, repeated measurements ANOVA were used with a Tukey's Post-Hoc Multiple Comparison Test. Additionally, Student's unpaired $t$-tests were performed to determine differences in implant surface properties between the non coated (Ti, GB, $\mathrm{GAE}$ ) and coated surfaces. Differences were considered statistically significant at $\mathrm{p}<0.05$.

\section{Results}

For the in vivo evaluation of the performance of the different surface modifications, a bone conduction chamber cassette model on the goat transverse process was used to evaluate the osteophilic capacity of different surface modifications within one in vivo experimental setup. Bone area, bone-to-implant contact, and maximum bone height were determined inside each individual chamber after a twelve-week implantation period. This histomorphometrical data set demonstrated that plasma-sprayed CaP coatings had a superior bone response compared to non coated surfaces (Ti, GB, and GAE).

\subsection{Surface topographical analysis}

Surface topographical evaluation of the surface modifications (after subtractive or additive surface modification procedures) is presented in Table 1 . Mean surface roughness $\left(R_{a}\right)$ of unmodified, machined titanium (TI; $R_{a}=0.77 \mu \mathrm{m} \pm 0.08 \mu \mathrm{m}$ ) increased upon grit blasting $\left(\mathrm{GB} ; \mathrm{R}_{\mathrm{a}}=1.22 \mu \mathrm{m} \pm 0.13 \mu \mathrm{m}\right)$ and acid etching (GAE; $\left.R_{a}=1.04 \mu \mathrm{m} \pm 0.13\right)$. Generally, mean surface roughness after coating deposition (i.e. PLD, ESD, biomimetic precipitation and magnetron sputtering) ranged from $R_{a}=1.04$ to $1.64 \mu \mathrm{m}$. However, plasma-sprayed coatings exhibited significantly $(p<0.05)$ rougher surfaces with $R_{a}=6.95-7.13 \mu \mathrm{m}$. Scanning electron microscopy (SEM) visually confirmed the $R_{a}$-based micro-topographical differences seen between experimental surfaces (Fig. 3 ).

All coating procedures demonstrated homogenous surface coverage. A flake-like structure was visible for the biomimetic coating procedure, while the plasma-sprayed coatings revealed a globular and spherical morphology reflecting partial melting of precursor powders. XRD patterns of the experimental surfaces confirmed
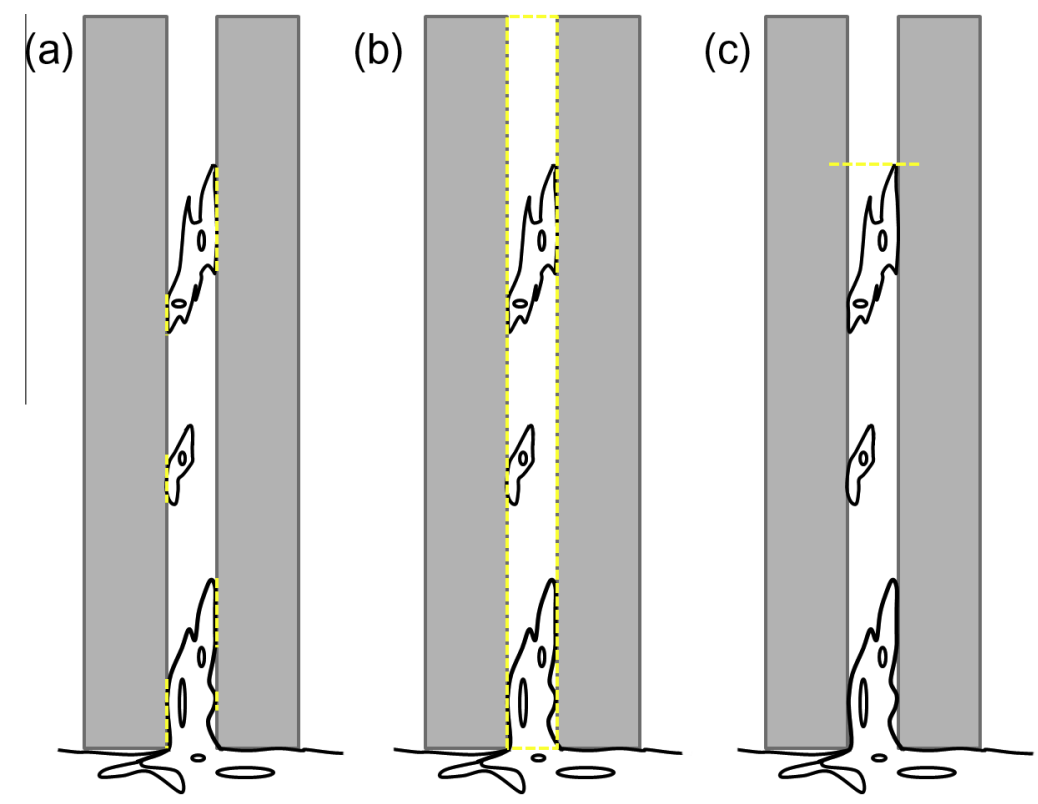

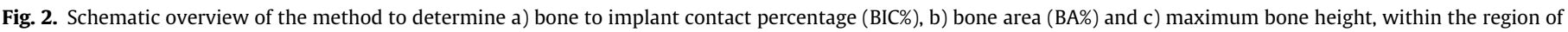
interest (red box). (For interpretation of the references to colour in this figure legend, the reader is referred to the web version of this article.) 

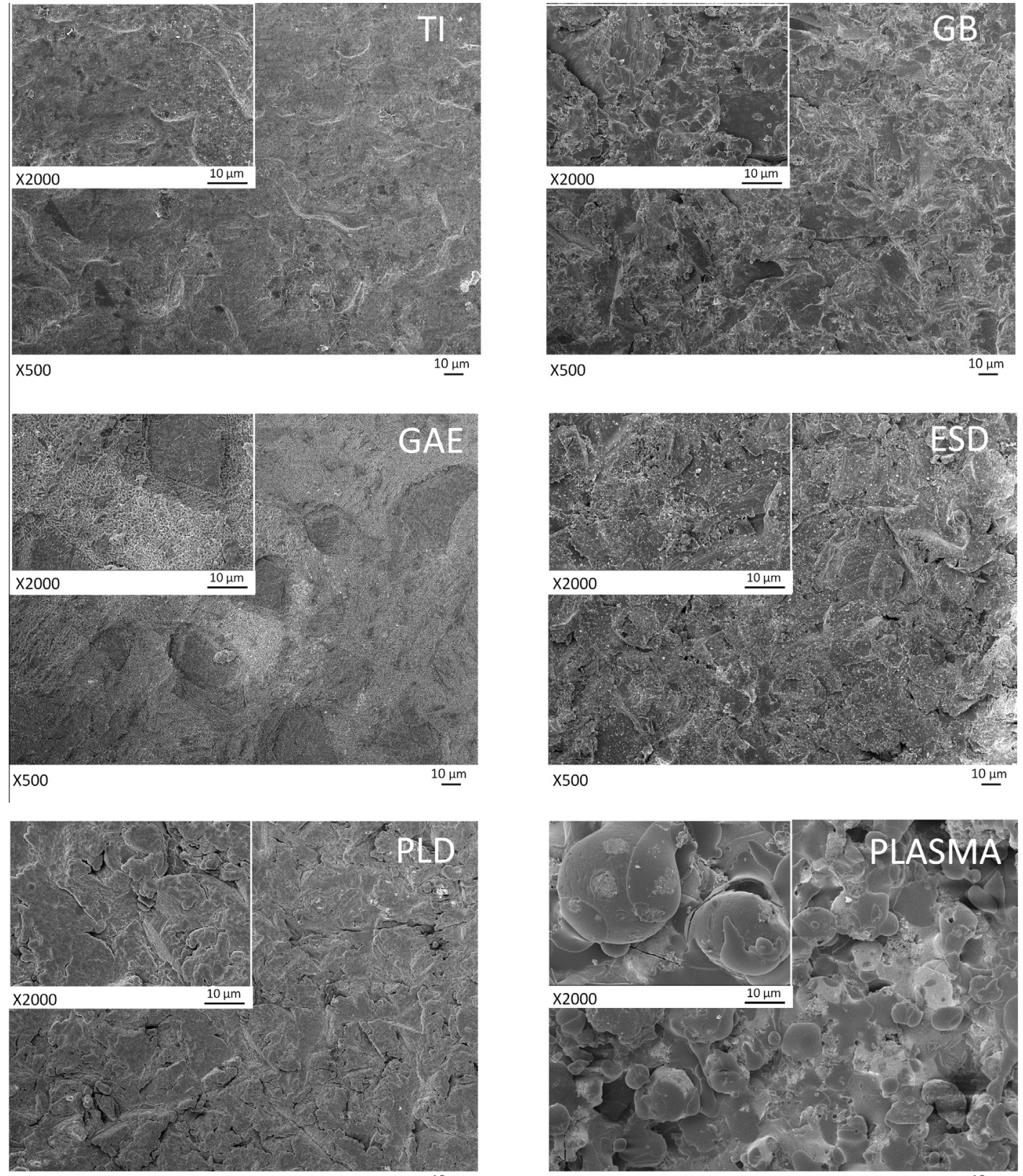

X500

$10 \underline{\mu m}$

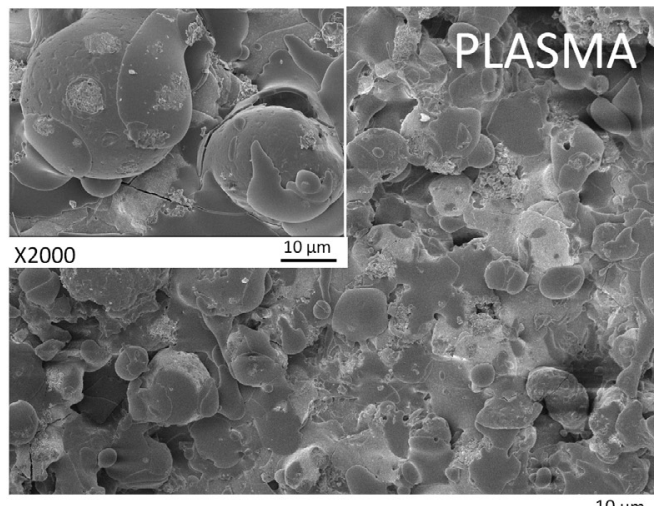

X500

$\underline{10 \mu \mathrm{m}}$
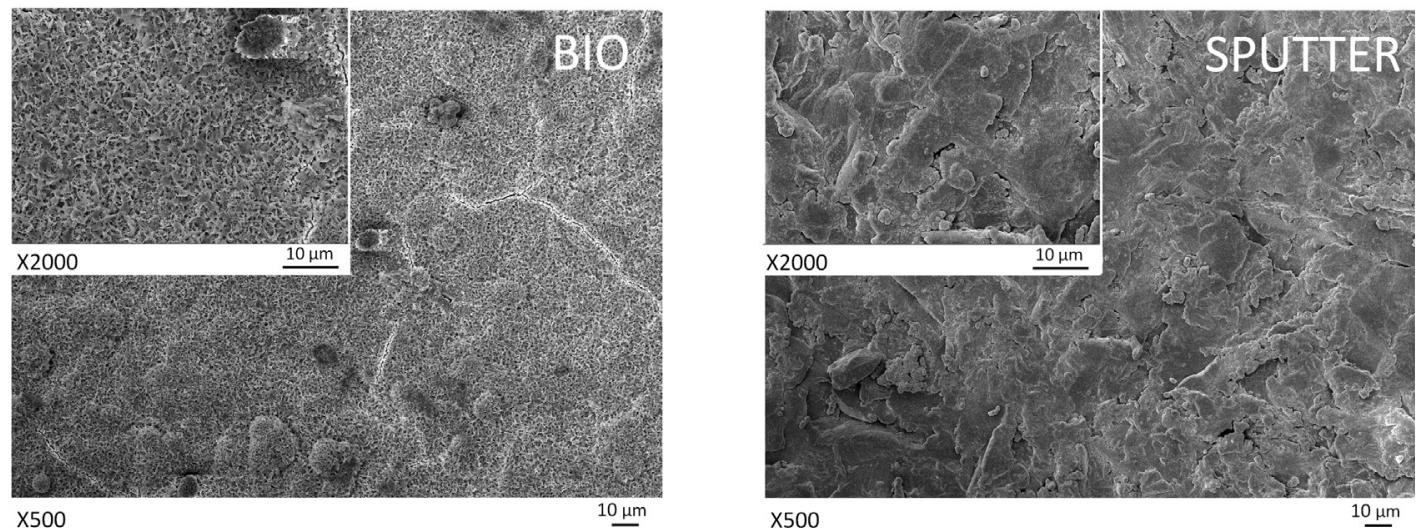

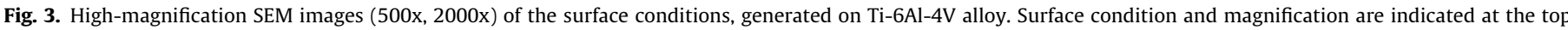
right and bottom of the image. 

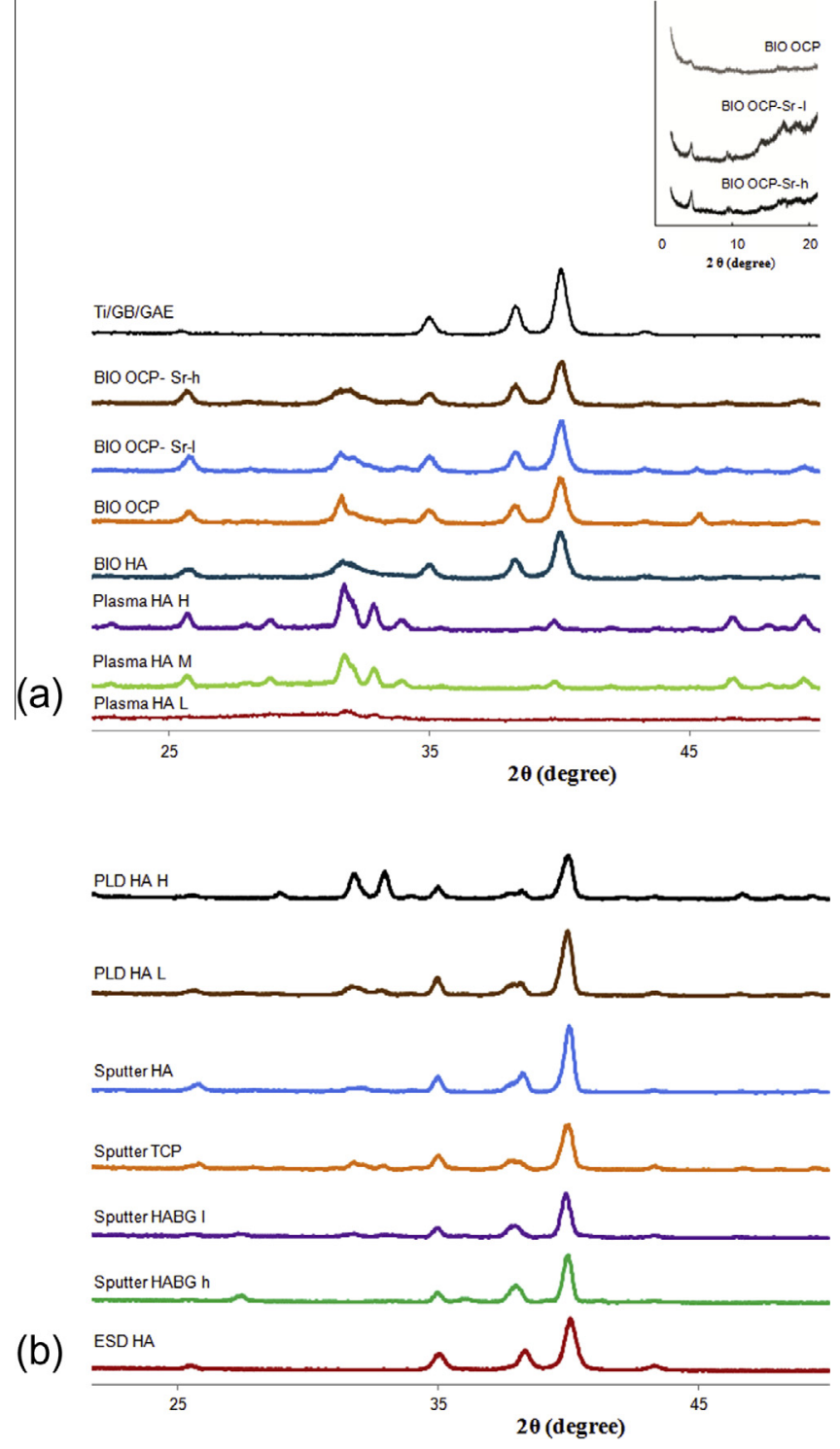

Fig. 4. XRD analysis of the generated coatings on Ti after heat treatment. a) $>50 \mu \mathrm{m}$ thickness, b) $<50 \mu \mathrm{m}$ thickness.

that most coatings displayed reflection peaks characteristic for apatite at $26^{\circ}$ and $32^{\circ} 2 \theta$. Thin ESD, magnetron sputtering coatings, and non coated Ti substrates, however, did not display these peaks. Coatings generated by a biomimetic approached also displayed characteristic reflection peaks for OCP at $4.2^{\circ} 2 \theta$ (Fig. 4a-b). Coating thickness measurements revealed that experimental coatings could be categorized into two groups; i) high thickness $(>50 \mu \mathrm{m})$ for plasma-sprayed and biomimetic coatings and ii) low thickness $(<50 \mu \mathrm{m})$ generated by PLD, ESD or magnetron sputtering.

\subsection{In vitro dissolution study}

Table 2 presents the results of the in vitro dissolution/reprecipitation behavior for the different coatings after 7 and 14 days of immersion in SBF with an ionic concentration similar to physiological fluid. For the thick coatings (i.e. plasma-spayed and biomimetic coatings), a decrease of Ca concentration was observed after 7 days, indicating a net uptake of calcium from the SBF solution. Thereafter, the Ca concentration remained stable. Except for PLD-HA-L and Sputter-HABG-l, all thin coatings demonstrated a stable Ca concentration after 7 days, indicating that there was no net difference in the release/uptake process. Also after 14 days in SBF, the Ca concentration remained stable for the thin coatings.

\subsection{Animal experiment}

\subsubsection{General observations}

Surgical procedures proceeded without complication. Postoperative recovery was uneventful and all animals remained in good overall condition, without signs of infections or impaired function. At implant retrieval, no signs of inflammation were observed and the chamber cassettes were well attached to the underlying bone of the transverse processes.

\subsubsection{Histological evaluation}

Histological analysis of the chamber cassettes demonstrated uneventful healing without any signs of an inflammatory response. Fibrous tissue ingrowth from the overlying soft tissues into the osteoconductive channels was observed for most of the cassettes. Occasionally, an intervening layer of soft tissue was observed between the titanium scaffold and the underlying decorticated transverse processes. Overall, longitudinal bone ingrowth appeared in most of the channels, starting from the dorsal base of the transverse process into the channels in a needle-like architecture. For most of the surface modifications, no significant bone apposition was observed on the surface modified walls of the chamber. Interestingly, for the plasma-sprayed coatings, a clear osteoconductive pattern was observed on the coated surface (Fig. 5a). At higher magnification, osteocytes could be distinguished in the newly formed bone tissue on the plasma-sprayed surfaces. These cells are indicative of bone maturation and lamellar bone formation (Fig. 5b).

Backscattered electron microscopy (BSEM) revealed cracks in a number of the samples due to histological processing and MMA embedding. BSEM and histological sections showed comparable qualitative bone formation patterns in the osteoconductive channels (Fig. 5c). The black arrows in Fig. $5 c$ point to crack regions.

\subsubsection{Histomorphometrical analysis}

Standardized measurements of the individual regions of interest (ROI) demonstrated equal areas for the different surface modifications (Fig. 6). Bone formation was histomorphometrically quantified after 12 weeks of healing in terms of $\mathrm{BIC} \%, \mathrm{BA} \%$ and $\mathrm{BH}$ in an individualized ROI in each osteoconductive channel. Data are displayed in box plots (Fig. 7).

In Fig. 7a, BIC\% is graphically depicted for the different surface modifications. After 12 weeks (low (L), medium (M) and high $(\mathrm{H})$ ) crystalline plasma-sprayed coatings demonstrated significantly (P<0.01; Fig. 7a) higher BIC\% (L: $19.8 \pm 11.4 \%$; $\mathrm{M}$ : $21.7 \pm 7.8 \%$; $\mathrm{H}: 15.8 \pm 12.6 \%$ ) compared to non coated surfaces (Ti: $0.9 \pm 0.6 \%$; GB: $2.3 \pm 1.3 \%$; GAE: $2.0 \pm 1.8 \%$ ). Regarding BA\%, plasma-sprayed coatings demonstrated significantly $(\mathrm{p}<0.01$; Fig. 7b) higher relative bone mass in the channels ( $\mathrm{L}: 11.7 \pm 8.1 \%$; M: $13.3 \pm 1.9 \%$; $: 12.3 \pm 5.5 \%$ ) compared to non coated surfaces (Ti: $1.1 \pm 1.1 \%$; GB: $1.6 \pm 1.2 \%$; GAE: $1.5 \pm 1.2 \%$ ). Fig. $7 \mathrm{c}$ shows the data on maximum bone height for the different surface conditions. In the present study, only plasma-sprayed coatings demonstrated significantly $(\mathrm{p}<0.01)$ higher maximum bone peaks after 12 weeks (L: $\quad 2919.4 \mu \mathrm{m} \pm 2350.6 \mu \mathrm{m} ; \quad \mathrm{M}: \quad 3334.3 \pm 1816.5 \mu \mathrm{m} ; \quad \mathrm{H}$ : $3373.7 \pm 2871.5 \mu \mathrm{m}$ ), in comparison to non coated surfaces (Ti: $379.3 \pm 301.1 \mu \mathrm{m}$; GB: $896.2 \pm 533.5 \mu \mathrm{m}$; GAE: $634.0 \pm 554.7 \mu \mathrm{m}$ ).

\section{Discussion}

Many preclinical animal models are available for evaluation of the osteophilic properties of titanium implant surfaces. These 
(a)

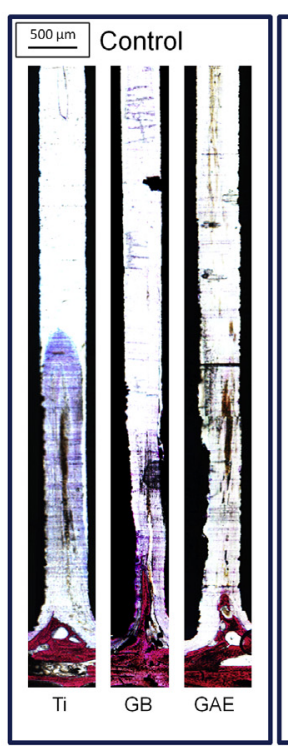

(b)
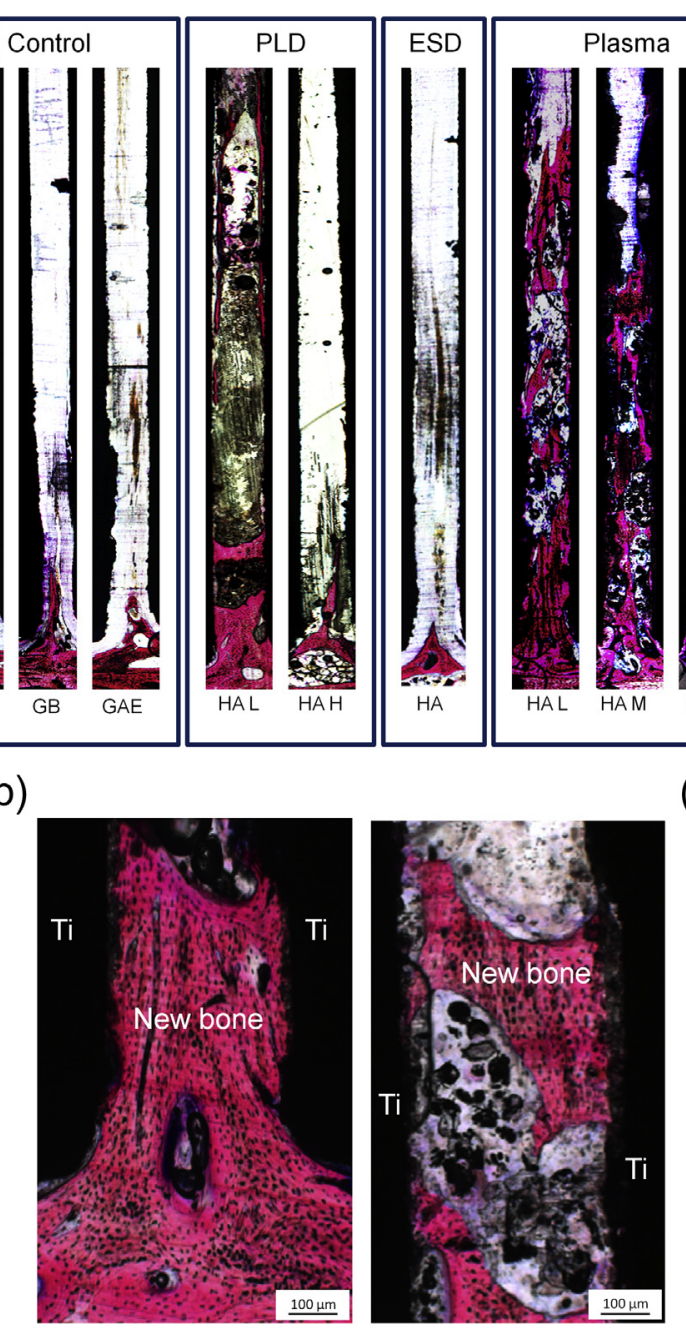
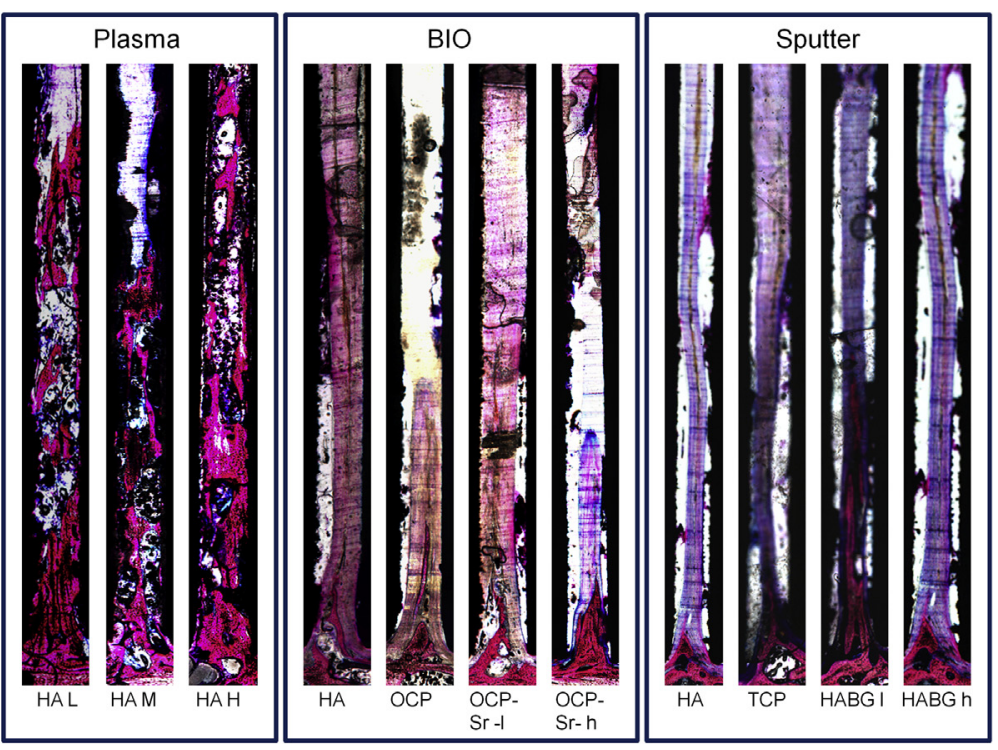

(c)
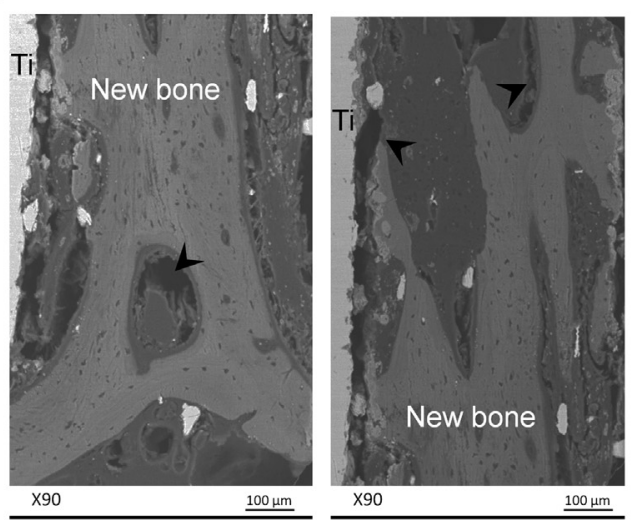

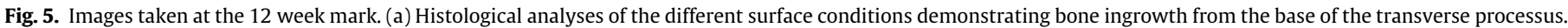

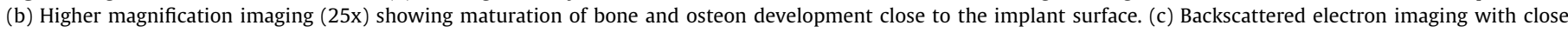
resemblance to the histological stained sections. Black arrows indicate cracks in the MMA due to histological processing.

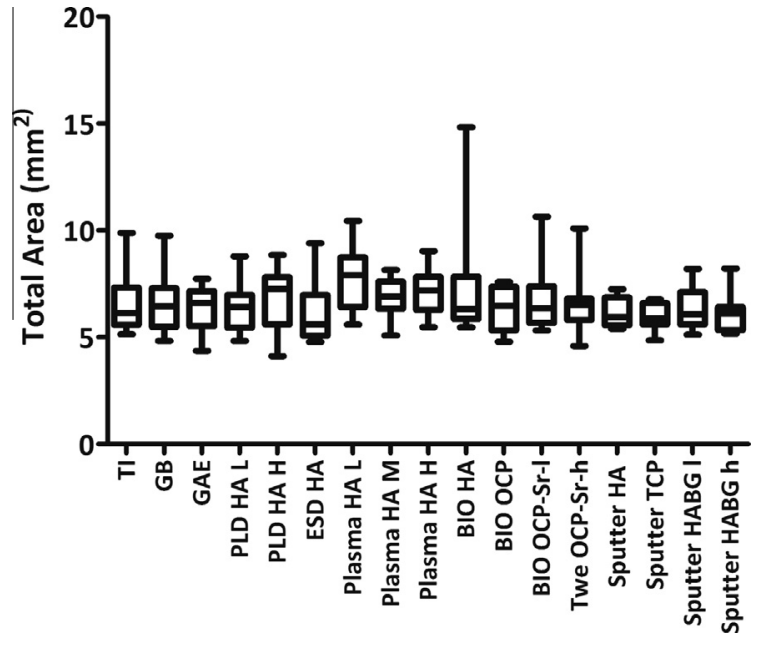

Fig. 6. Box-and-whisker plot showing the total bone area (BA) of the osteoconductive channels for each surface modification. Total BA for the thick coatings $(>50 \mu \mathrm{m})$ was approximately the same size as the thinner coatings $(<50 \mu \mathrm{m})$. models, however, have a number of drawbacks. First, these models place the implant in regions that are completely surrounded by native bone $[47,48]$. This ideal osseous environment likely confounds osteophilicity related implant surface effects. These models then are unable to isolate the impact of implant surface properties on the bone tissue response [49]. Second, these models do not accurately simulate the clinical environment. In the clinic, implants are frequently placed in cases in which a gap is present between the implant surface and the native bone, such as cases that involve implant placement immediately after tooth extraction [50]. In these cases, an implant is desired with optimal osteophilic characteristics that stimulates conductive bone apposition from the native bone and spreading towards implant surface [51,52]. Third, these models only allow a limited number of surface implant comparisons because of the restricted anatomical location. Given that we were interested in both evaluating the osteophilic capacity of a broad range of different surface modifications within one in vivo experimental setup, and simulating a challenging clinical environment as closely as possible, a bone conduction chamber cassette model was used on the transverse process of a goat. The bone-chamber cassette model in its current design was originally developed and validated by Wilson et al. in 2005. This model allows accurate evaluation of the osteoconductive properties of 
(a)

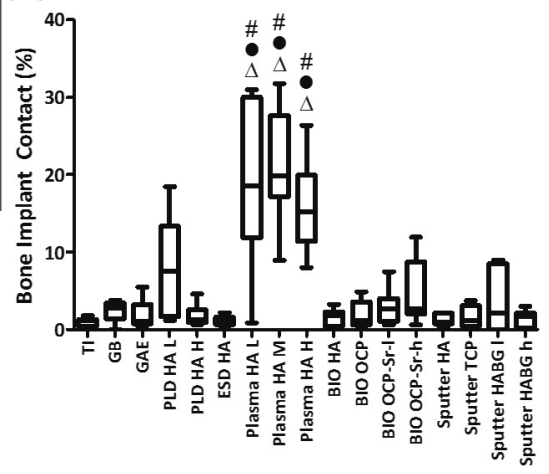

(b)

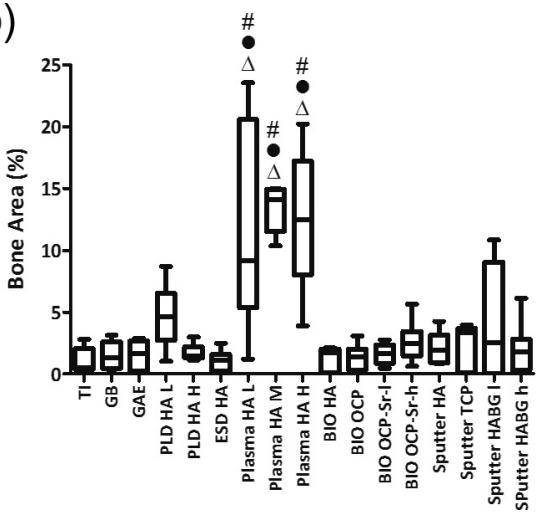

(c)

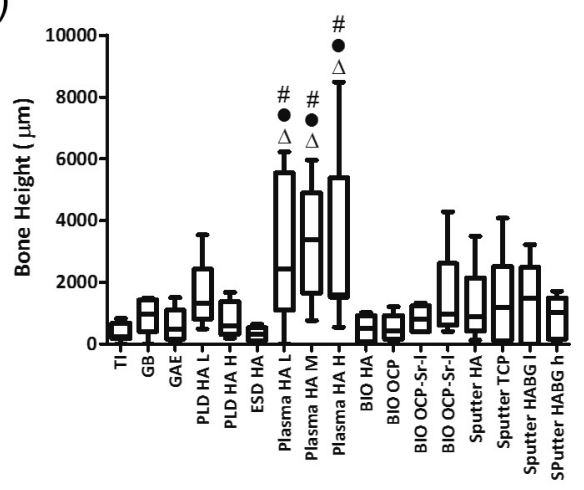

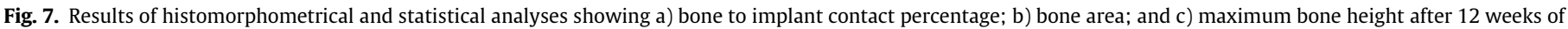

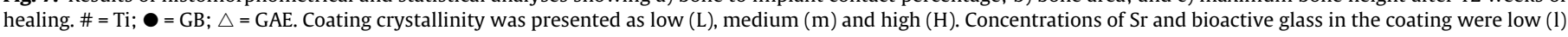
and high (h)

biomaterials, and their impact on bone metabolism in an unloaded environment [45]. In this study, the placement of the cassettes on decorticated bone allowed for discrimination of surface property effects on several histomorphometrical parameters (i.e. boneimplant contact, bone area, and bone height) related to osteophilicity.

Histological evaluation demonstrated that bone formation occurred in two ways. First, bone formed from the base of the transverse process into the chambers with a needle-like architecture. Previous studies have shown that this type of bone formation is likely representative of bone ingrowth, and is not related to implant surface osteoconductive properties. Instead, such growth is likely related to capillary filling of the chamber [45]. Appositional bone growth was the other type of bone formation seen histologically. This bone growth was observed along the modified surfaces flanking the channel and was osteoconductive. Previous research has shown that appositional bone growth in the context of bone implants is likely influenced by the implant surface. This type of bone formation is related to the degree of spreading and migration of (pre)osteogenic cells on the implant surface, and subsequently the amount of bone ingrowth and bone contact on the implant surface $[16,45]$. This appositional bone formation was observed most often for implants with plasma-sprayed CaP coatings.

Histomorphometrical analyses (BIC\% and $\mathrm{BA} \%$ ) indicated that plasma-sprayed $\mathrm{CaP}$ coatings have a beneficial effect on bone formation compared to non coated controls. This observation agrees with earlier findings that demonstrated that CaP plasma-sprayed coatings positively influence early bone response around titanium bone implants [37,39]. The beneficial impact of CaP plasma sprayed coatings on appositional bone formation may be a result of their relatively higher surface roughness (Ra: $6.48-7.13 \mu \mathrm{m}$ ) compared to all other modified surfaces. The increase in microroughness seen in CaP plasma-sprayed coatings significantly increased the surface area available for precipitation of a carbonated apatite layer as well as protein adsorption. This result does not agree with the generally accepted moderately roughness values (Ra 1-2 $\mu \mathrm{m}$ ) for optimal peri-implant bone formation. However, a systematic review by Shalabi et al. (2006) [71] demonstrated that a broader range of surface roughness ( $\mathrm{Ra} / \mathrm{Sa}$ $0.5-8.5 \mu \mathrm{m}$ ) positively influences the peri-implant bone response.

The positive biological response to the plasma-sprayed implant surface can also be attributed to partial dissolution of amorphous regions within plasma-sprayed CaP coatings resulting into release of calcium $\left(\mathrm{Ca}^{2+}\right)$ and phosphate $\left(\mathrm{PO}_{4}^{3-}\right)$ ions in the peri-implant region [22]. The precise mechanism behind the influence of $\mathrm{Ca}^{2+}$ ions on bone remodeling has not been completely elucidated. However, several authors have suggested that local $\mathrm{Ca}^{2+}$ ion super-saturation within the peri-implant region influences the morphology and osteogenic differentiation of pre-osteoblasts [53]. Additionally, the presence of $\mathrm{Ca}^{2+}$ ions has been shown to stimulate apatite nucleation and the precipitation of a carbonate calcium phosphate layer. This apatite layer shows a high degree of crystallographic resemblance to native bone which allows for the attraction of proteins to the implant surface that trigger osteogenic cells to form bone [26].

Our in vitro coating stability assessment demonstrated no significant net release of $\mathrm{Ca}^{2+}$ ions from the different thin coatings into the solution, except for low crystalline PLD-HA-L coatings and Sputter-HABG-l coatings. In contrast, after 7 days of immersion in SBF, a decrease in Ca concentration in the SBF solution was observed for thick coatings, indicating a net uptake of calcium from the SBF rather than dissolution of the coatings.

Interestingly, coating crystallinity, irrespective of the applied coating deposition procedure, had no significant histomorphometrical impact on bone formation after 12 weeks of healing. This result agrees with previous in vivo work done by Chang et al., where titanium implants containing $\mathrm{CaP}$ coatings with different degrees of crystallinity were not found to influence early bone formation. Further, Chang et al. found that CaP-coating enhanced early bone formation in comparison to non coated implants [72]. Still, there is evidence showing that amorphous plasma-sprayed CaP coatings are beneficial for the early in vivo bone response because of higher dissolution rates of calcium $\left(\mathrm{Ca}^{2+}\right)$ and phosphate $\left(\mathrm{PO}_{4}^{3-}\right)$ ions in comparison to high crystalline plasma-sprayed $\mathrm{CaP}$ coatings [54].

In the present study, ceramic coatings were generated, based on different phases of CaP ceramics (i.e. HA, OCP and TCP), as a composite coating incorporating bioactive glass or by the addition of therapeutic agents (i.e. strontium). In order to generate these coatings, different deposition techniques (PLD, ESD, magnetron sputtering, plasma-spraying by biomimetic precipitation) were used that resulted in a significant variation in coating thickness. Coating deposition by PLD, ESD and magnetron sputtering generated relatively thin $(<50 \mu \mathrm{m})$ coatings, whereas after plasma spraying and biomimetic precipitation, relatively thick $(>50 \mu \mathrm{m})$ coatings were obtained. In view of the effects of coating thickness on the region of interest and related quantitative histomorphometric parameters, our measurements demonstrated equal regions of interest among the groups, which makes that our quantitative assessment 
can be regarded as reliable. Moreover, this also rules out effects of coating thickness on the quantitative parameters themselves, leaving other properties as remaining possible causes for histomorphometric differences.

Composite bioactive glass (BG) and HA coatings with a high $(\mathrm{H})$ and low (L) concentration were evaluated in this study. Based on previous literature [33,55], we hypothesized that these coatings possessed higher bioactive potential in comparison to pure CaP coatings due to the formation of a hydrated silica layer and hydroxyl carbonate apatite (HCA). This layer not only resembles the mineral phase of bone, but also has a stimulating effect on osteoblast differentiation [34,35]. Although a tendency towards a higher bone-area was noticeable for the HABG (1) coating, no significant differences were observed between the HABG coatings and the non coated surfaces. The lack of an effect may have been because the HABG coatings were too thin to form such a silica layer [56]. Another possible explanation could be found in the coating procedure itself. Previous in vitro data has demonstrated that magnetron sputtering can change the elemental composition of the BG target material. As a result, the weight percentage $\mathrm{SiO}_{2}$ in the coating decreases $<40 \%$ [57]. This negatively affects the osteophilic properties of the coating, since it is well known from the literature that only bioactive glasses with weight percentages $\mathrm{SiO}_{2}$ between $40 \%$ and $60 \%$ have osteophilic properties [56,58].

For two of the OCP coatings, high (h) and low (l) concentrations of strontium $(\mathrm{Sr})$ were incorporated into the coating because strontium has an established effect on bone turnover and has a close chemical resemblance to calcium ions [59]. Although the precise mechanism of strontium's effects is unclear, it is thought that strontium reduces bone resorption while stimulating bone formation in vivo, especially under osteopenic conditions $[59,60]$. However, our OCP-Sr coating histomorphometrical data showed no beneficial osteoconductive effect. We speculate that the therapeutic dose of $\mathrm{Sr}$ in the coatings was too small to have a significant additive effect on the bioactive properties of the coating.

It should be emphasized that the absence of statistically significant differences in bone response between some of the coated and non coated surfaces are likely a result of the heterogeneous Saane goat population used in this study. Most in vivo studies on surface modifications include highly standardized and homogenous animal populations (i.e. mostly rodents) with a uniform genetic background. For the present study, goats were obtained with a certain variation in age and weight. This can be considered a rather heterogeneous population with a significant variation in bone response resulting in histomorphometrical data with relatively large standard deviations. However, a heterogeneous experimental population partly resembles the clinical situation where large variations in patient age and weight are seen.

In summary, this study demonstrated that the deposition of high roughness CaP coating has a beneficial effect on the osteophilic capacity of titanium in a chamber cassette model. More research, however, is needed to unravel the surface physicochemical properties and bone formation mechanisms responsible for this biological response.

\section{Conclusions}

It can be concluded that (i) the chamber cassette model is a valid model to determine the in vivo effect of different surface characteristics on the osteophilicity of a titanium implant surface in one individual animal, and (ii) under the current experimental conditions, plasma-sprayed CaP coatings have a superior osteophilic effect compared to non coated titanium surfaces and a wide range of $\mathrm{CaP}$ and/or bioactive glass-based coatings deposited using alternative techniques.

\section{Acknowledgements}

The authors would like to acknowledge Mr. Vincent Cuijpers for his assistance with histomorphometrical analyses, and Ms. Natasja van Dijk for her assistance with the histological sectioning. We would like to thank Editage (www.editage.com) for English language editing. This research forms part of the Project P2.04 BONE-IP of the research program of the BioMedical Materials institute, co-funded by the Dutch Ministry of Economic Affairs, Agriculture and Innovation.

\section{References}

[1] K. Christensen, G. Doblhammer, R. Rau, J.W. Vaupel, Ageing populations: the challenges ahead, Lancet 374 (2009) 1196.

[2] E.M. Christenson, K.S. Anseth, J.J. van den Beucken, R.S. Tuan, A.G. Mikos, Nanobiomaterial applications in orthopedics, J. Orthop. Res. 25 (2008) 11.

[3] P.O. Ostman, M. Hellman, L. Sennerby, A. Wennerberg, Temporary implantsupported prosthesis for immediate loading according to a chair-side concept: technical note and results from 37 consecutive cases, Clin. Implant Dent. Relat. Res. 10 (2008) 71.

[4] P.F. Allen, A.S. McMillan, A longitudinal study of quality of life outcomes in older adults requesting implant prostheses and complete removable dentures, Clin. Oral Implant Res. 14 (2003) 173.

[5] W. Sonoyama, T. Kuboki, S. Okamoto, H. Suzuki, A. Yamashita, Quality of life assessment in patients with implant-supported and resin-bonded fixed prosthesis for bounded edentulous spaces, Clin. Oral Implant Res. 13 (2002) 359.

[6] U. Lekholm, J. Gunne, P. Henry, K. Higuchi, U. Linden, C. Bergstrom, D. van Sgteenberghe, Survival of the Branemark implant in partially edentulous jaws: a 10-year prospective multicenter study, Int. J. Oral Maxillofac. Implant 14 (1999) 639.

[7] J.P. Becktor, S. Isaksson, L. Sennerby, Survival analysis of endosseous implants in grafted and nongrafted edentulous maxillae, Int. J. Oral Maxillofac. Implant 19 (2004) 107

[8] M. Esposito, J.M. Hirsch, U. Lekholm, P. Thomsen, Biological factors contributing to failures of osseointegrated oral implants (I). Success criteria and epidemiology, Eur. J. Oral Sci. 106 (1998) 527.

[9] M. Fini, G. Giavaresi, P. Torricelli, A. Carpi, Osteoporosis and biomaterial osteointegration, Biomed. Pharmacother. 58 (2004) 487.

[10] A. Wennerberg, T. Albrektsson, B. Andersson, An animal study of Cp titanium screws with different surface topographies, J. Mater. Sci. - Mater. Med. 6 (1995) 302 (May, 1995).

[11] L. Le Guehennec, A. Soueidan, P. Layrolle, Y. Amouriq, Surface treatments of titanium dental implants for rapid osseointegration, Dent. Mater. 23 (2007) 844.

[12] D. Buser, N. Broggini, M. Wieland, A. Lussi, S.G. Steinemann, Enhanced bone apposition to a chemically modified SLA titanium surface, J. Dent. Res. 83 (2004) 529.

[13] M.M. Bornstein, P. Valderrama, A.A. Jones, T.G. Wilson, R. Seibl, D.L. Cochran, Bone apposition around two different sandblasted and acid-etched titanium implant surfaces: a histomorphometric study in canine mandibles, Clin. Oral Implant Res. 19 (2008) 233.

[14] L.T. de Jonge, S.C. Leeuwenburgh, J.G. Wolke, J.A. Jansen, Organic-inorganic surface modifications for titanium implant surfaces, Pharm. Res. 25 (2008) 2357.

[15] R. Junker, A. Dimakis, M. Thoneick, J.A. Jansen, Effects of implant surface coatings and composition on bone integration: a systematic review, Clin. Oral Implant Res. 20 (2009) 185.

[16] J.E. Davies, Understanding peri-implant endosseous healing, J. Dent. Educ. 67 (2003) 932.

[17] C.H. Lohmann, E.M. Tandy, D.D. Dean, B.D. Boyan, Z. Schwartz, Response of normal female human osteoblasts (NHOst) to 17beta-estradiol is modulated by implant surface morphology, J. Biomed. Mater. Res. 62 (2002) 204.

[18] F. Barrere et al., Osteointegration of biomimetic apatite coating applied onto dense and porous metal implants in femurs of goats, J. Biomed. Mater. Res. B Appl. Biomater. 67 (2003) 655.

[19] J.A. Jansen, J.P. van de Waerden, J.G. Wolke, K. de Groot, Histologic evaluation of the osseous adaptation to titanium and hydroxyapatite-coated titanium implants, J. Biomed. Mater. Res. 25 (1991) 973.

[20] M.C. Siebers, J.G. Wolke, X.F. Walboomers, S.C. Leeuwenburgh, J.A. Jansen, In vivo evaluation of the trabecular bone behavior to porous electrostatic spray deposition-derived calcium phosphate coatings, Clin. Oral Implant Res. 18 (2007) 354.

[21] L.I. Havelin, L.B. Engesaeter, B. Espehaug, O. Furnes, S.A. Lie, S.E. Vollset, The Norwegian Arthroplasty Register: 11 years and 73,000 arthroplasties, Acta Orthop. Scand. 71 (2000) 337.

[22] G. Daculsi, O. Laboux, O. Malard, P. Weiss, Current state of the art of biphasic calcium phosphate bioceramics, J. Mater. Sci. - Mater. Med. 14 (2003).

[23] W.J. Boyle, W.S. Simonet, D.L. Lacey, Osteoclast differentiation and activation, Nature 423 (2003) 337. 
[24] Y.C. Chai, A. Carlier, J. Bolander, H. Van Oosterwyck, F.P. Luytebn, Current views on calcium phosphate osteogenicity and the translation into effective bone regeneration strategies, Acta Biomater. 8 (2012) 3876.

[25] C. Itthichaisri, M. Wiedmann-Al-Ahmad, U. Huebner, A. Al-Ahmad, N.C. Gellrich, Comparative in vitro study of the proliferation and growth of human osteoblast-like cells on various biomaterials, J. Biomed. Mater. Res. A 82 (2007) 777.

[26] P.J. ter Brugge, J.A. Jansen, Initial interaction of rat bone marrow cells with non-coated and calcium phosphate coated titanium substrates, Biomaterials 23 (2002) 3269.

[27] R.J. Dekker, J.D. de Bruijn, M. Sitger, F. Barrere, P. Payrolle, C.A. van Blitterswijk, Bone tissue engineering on amorphous carbonated apatite and crystalline octacalcium phosphate-coated titanium discs, Biomaterials 26 (2005) 5231.

[28] A.M. Barradas, H. Yuan, C.A. van Blitterswijk, P. Habibovic, Osteoinductive ceramics as a synthetic alternative to autologous bone grafting, Proc. Natl. Acad. Sci. U.S.A. 107 (2010) 13614.

[29] R. Bosco, E.R.U. Edreira, J.G.C. Wolke, S.C.G. Leeuwenburgh, J.J.J.P. van den Beucken, J.A. Jansen, Instructive coatings for biological guidance of bone implants, Surf. Coat. Technol. 233 (2013) 91.

[30] S. Mohammadi, M. Esposito, J. Hall, L. Emanuelsson, A. Krozer, P. Thomsen, Long-term bone response to titanium implants coated with thin radiofrepuent magnetron-sputtered hydroxyapatite in rabbits, Int. J. Oral Maxillofac. Implant 19 (2004) 498.

[31] S.C. Leeuwenburgh, J.G. Wolke, J. Schoonman, J.A. Jansen, Influence of precursor solution parameters on chemical properties of calcium phosphate coatings prepared using Electrostatic Spray Deposition (ESD), Biomaterials 25 (2004) 641.

[32] F. Barrere, C.M. van der Valk, R.A.J. Dalmeijer, G. Meijer, C.A. van Blitterswijk, K. de Groot, P. Layrolle, Osteogenecity of octacalcium phosphate coatings applied on porous metal implants, J. Biomed. Mater. Res. A 66A (2003) 779.

[33] H.P. Yuan, J.D. de Bruijn, X.D. Zhang, C.A. van Blitterswijk, K. de Groot, Bone induction by porous glass ceramic made from Bioglass (R) (45S5), J. Biomed. Mater. Res. 58 (2001) 270.

[34] L.L. Hench, The story of Bioglass (R), J. Mater. Sci. - Mater. Med. 17 (2006) 967.

[35] I.D. Xynos, M.V.J. Hukkanen, J.J. batten, L.L. Hench, J.M. Polak, Bioglass (R) 45S5 stimulates osteoblast turnover and enhances bone formation in vitro: Implications and applications for bone tissue engineering, Calcif. Tissue Int. 67 (2000) 321.

[36] J.A. Jansen, J.P.C.M. Vanderwaerden, J.G.C. Wolke, Histologic investigation of the biologic behavior of different hydroxyapatite plasma-sprayed coatings in rabbits, J. Biomed. Mater. Res. 27 (1993) 603.

[37] S. Vercaigne, J. Naert, J.G.C. Wolke, J.A. Jansen, Bone healing capacity of titanium- and hydroxylapatite plasmasprayed coated oral implants, J. Dent. Res. 77 (1998) 769.

[38] M. Gottlander, C.B. Johansson, T. Albrektsson, Short and long-term animal studies with a plasma-sprayed calciumn phosphate-coated implant, Clin. Oral Implant Res. 8 (1997) 345.

[39] J.L. Ong, K. Bessho, D.L. Carnes, Bone response to plasma-sprayed hydroxyapatite and radiofrequency-sputtered calcium phosphate implants in vivo, Int. J. Oral Maxillofac. Implant 17 (2002) 581.

[40] D. Schwartz-Arad, O. Mardinger, L. Levin, A. Kozlovsky, A. Hirshberg, Marginal bone loss pattern around hydroxyapatite-coated versus commercially pure titanium implants after up to 12 years of follow-up, Int. J. Oral Maxillofac. Implants 20 (2005) 238.

[41] F.J. Garcia-Sanz, M.B. Mayor, J.L. Arias, J. Pou, B. Leon, M. Perez-Amor, Hydroxyapatite coatings: a comparative study between plasma-spray and pulsed laser deposition techniques, J. Mater. Sci. - Mater. Med. 8 (1997) 861 (Dec, 1997).

[42] A.V. Xiropaidis et al., Bone-implant contact at calcium phosphate-coated and porous titanium oxide (TiUnite ${ }^{\mathrm{TM}}$ )-modified oral implants, Clin. Oral Implants Res. 16 (2005) 532

[43] A.W. Nijhuis, S.C. Leeuwenburgh, J.A. Jansen, Wet-chemical deposition of functional coatings for bone implantology, Macromol. Biosci. 10 (2010) 1316.

[44] A.L. Oliveira, R.L. Reis, P. Li, Strontium-substituted apatite coating grown on Ti6Al4V substrate through biomimetic synthesis, J. Biomed. Mater. Res. B Appl. Biomater. 83 (2007) 258.

[45] C.E. Wilson, M.C. Kruyt, J.D. de Bruijn, C.A. van Blitterswijk, W.J. Dhert, A new in vivo screening model for posterior spinal bone formation: comparison of ten calcium phosphate ceramic material treatments, Biomaterials 27 (2006) 302 (Jan, 2006).

[46] M.C. Kruyt, C.E. Wilson, J.D. de Bruijn, C.A. van Blitterswijk, A.J. Verbout, W.] Dhert, The effect of cell-based bone tissue engineering in a goat Transverse process model, Biomaterials 27 (2006) 5099.

[47] C. Schouten, G.J. Meijer, J.J.J.P. van den Beucken, P.H.M. Spauwen, J.A. Jansen, A novel implantation model for evaluation of bone healing response to dental implants: the goat iliac crest, Clin. Oral Implant Res. 21 (2010) 414.
[48] T. Berglundh, I. Abrahamson, J.P. Albouy, J. Lindhe, Bone healing at implants with a fluoride-modified surface; an experiemtnal study in dogs, Clin. Oral Implant Res. 18 (2007) 147.

[49] B. van Oirschot, H.S. Alghamdi, T.O. Nahri, S. Anil, J.J. van den Beucken, J.A. Jansen, In vivo evaluation of bioactive glass-based coatings on dental implants in a dog implantation model, Clin. Oral Implant Res. 25 (2014) 21.

[50] D. Botticelli, T. Berglundh, J. Lindhe, Hard-tissue alterations following immediate implant placement in extraction sites, J. Clin. Periodontol. 31 (2004) 820.

[51] C. Schouten, J.J. van den Beucken, L.T. de Jonge, P.H. Spauwen, J.A. Jansen, The effect of alkaline phosphatase coated onto titanium alloys on bone responses in rats, Biomaterials 30 (2009) 6407.

[52] H.S. Alghamdi, B.A. van Oirschot, R. Bosco, J.J. van den Beucken, S. Anil, J.A. Jansen, Biological response to titanium implants coated with nanocrystals calcium phosphate or type 1 collagen in a dog model, Clin. Oral Implant Res. 24 (2013) 475.

[53] A.M. Barradas, H.A. Fernandes, J.P. van Leuwen, C.A. van Blitterswijk, J. de Boer, A calcium-induced signaling cascade leading to osteogenic differentiation of human bone marrow-derived mesenchymal stromal cells, Biomaterials 33 (2012) 3205

[54] W.C. Xue, S.Y. Tao, X.Y. Liu, X.B. Zheng, C.X. Ding, In vivo evaluation of plasma sprayed hydroxyapatite coatings having different crystallinity, Biomaterials 25 (2004) 415.

[55] D.L. Wheeler, M.J. Montfort, S.W. McLoughlin, Differential healing response of bone adjacent to porous implants coated with hydroxyapatite and 45S5 bioactive glass, J. Biomed. Mater. Res. 55 (2001) 603.

[56] L.L. Hench, Bioactive materials: the potential for tissue regeneration, J. Biomed. Mater. Res. 41 (1998) 511.

[57] J.G.C. Wolke, E. Vandenbulcke, B. van Oirschot, J.A. Jansen, A study to the surface characteristics of RF magnetron sputtered bioglass - and calcium phosphate coatings, Key Eng. Mater. 284-286 (2005) 187.

[58] P. Saravanapavan, J.R. Jones, S. Verrier, R. Beilby, L.L. Hench, J.M. Polak, Binary $\mathrm{CaO}-\mathrm{SiO} 2$ gel-glasses for biomedical applications, Bio-Med. Mater. Eng. 14 (2004) 467.

[59] H.S. Alghamdi, J.A. Jansen, Bone regeneration associated with nontherapeutic and therapeutic surface coatings for dental implants in osteoporosis, Tissue Eng. Part B-Rev. 19 (2013) 233.

[60] Y.F. Li, G. Feng, E. Luo, X.G. Liu, J. Hu, Strontium ranelate treatment enhances hydroxyapatite-coated titanium screws fixation in osteoporotic rats, J. Orthop. Res. 28 (2010) 578.

[61] R.V. Lenth, Statistical power calculations, J. Anim. Sci. 85 (2007) E24.

[62] L. Cleries, E. Martinez, C. Sardin, J. Esteve, J.L. Morenza, Mechanical properties of calcium phosphate coatings deposited by laser ablation, Biomaterials 21 (2000) 967 (May, 2000).

[63] L.T. de Jonge, J.J. van den Beucken, S.C. Leeuwenburgh, J.G. Wolke, J.A. Jansen, In vitro responses to electrosprayed alkaline phosphatase/calcium phosphate composite coatings, Acta Biomater. 5 (2009) 2773.

[64] K. Degroot, R. Geesink, C.P.A.T. Klein, P. Serekian, Plasma sprayed coatings of hydroxylapatite, J. Biomed. Mater. Res. 21 (1987) 1375.

[65] P. Habibovic, F. Barrere, C.A. van Blitterswijk, K. de Groot, P. Layrolle, Biomimetic hydroxyapatite coating on metal implants, J. Am. Ceram. Soc. 85 (2002) 517.

[66] F. Barrere, P. Layrolle, C.A. Van Blitterswijk, K. De Groot, Biomimetic coatings on titanium: a crystal growth study of octacalcium phosphate, J. Mater. Sci. Mater. Med. 12 (2001) 529.

[67] P. Habibovic, C.M. van der Valk, C.A. van Blitterswijk, K. De Groot, G. Meijer, Influence of octacalcium phosphate coating on osteoinductive properties of biomaterials, J. Mater. Sci. - Mater. Med. 15 (2004) 373.

[68] P. Habibovic, C.M. van der Valk, C.A. van Blitterswijk, K. De Groot, G. Meijer, Biological performance of uncoated and octacalcium phosphate-coated Ti6Al4V, Biomaterials 26 (2005) 23.

[69] J.G. Wolke, K. van Dijk, H.G. Schaeken, K. de Groot, J.A. Jansen, Study of the surface characteristics of magnetron-sputter calcium phosphate coatings, J. Biomed. Mater. Res. 28 (1999) 1477.

[70] H.B. van der Lubbe, C.P. Klein, K. de Groot, A simple method for preparing thin (10 microM) histological sections of undecalcified plastic embedded bone with implants, Stain Technol. 63 (1988) 171.

[71] M.M. Shalabi, A. Gortemaker, M.A. Van’t Hof, J.A. Jansen, N.H. Creugers, Implant surface roughness and bone healing: a systematic review, J. Dent. Res. 85 (2006) 496.

[72] Y.L. Chang, D. Lew, J.B. Park, J.C. Keller, Biomechanical and morphometric analysis of hydroxyapatite-coated implants with varying crystallinity, J. Oral Maxillofac. Surg. 1096 (1999) 9.

[79] T. Kokubo, H. Takadama, How useful is SBF in predicting in vivo bone bioactivity? Biomaterials 27 (2006) 2907-2915. 